\title{
Dabigatran Versus Warfarin for Direct Current Cardioversion in Atrial Fibrillation
}

Sufyan Benamer · Debbie Lusty · Tamara Everington

Received: June 13, 2016 / Published online: July 25, 2016

(C) The Author(s) 2016. This article is published with open access at Springerlink.com

\begin{abstract}
Introduction: Direct current cardioversion (DCCV) is considered as the most effective treatment for atrial fibrillation (AF). $\mathrm{AF}$ is associated with an increased risk of thromboembolism, and DCCV may increase this risk. The current recommendation is, therefore, to anticoagulate for at least 3 weeks before DCCV and 4 weeks after the procedure.
\end{abstract}

Methods: A retrospective study of patients referred for elective DCCV as treatment for AF in Hampshire Hospitals NHS Foundation Trust was performed to compare the safety and efficacy of dabigatran with warfarin in this setting.

Results: During a 12-month period, 129 patients were referred for DCCV for the

Enhanced content To view enhanced content for this article go to http://www.medengine.com/Redeem/ D6E4F06019D92124.

\section{S. Benamer $(\square) \cdot T$. Everington}

Hemophilia, Haemostasis and Thrombosis Center, Hampshire Hospitals NHS Foundation Trust, Basingstoke, UK

e-mail: sofianbenamer@gmail.com

D. Lusty

Cardiology Department, Hampshire Hospitals NHS

Foundation Trust, Basingstoke, UK treatment of AF and 107 patients received DCCV. Fifty-four patients were anticoagulated with dabigatran, 42 patients with warfarin, and 11 patients with other direct oral anticoagulants (DOACs) with choice of agent determined following an informed discussion with the patient. The average number of days between the date of referral for DCCV and the date of DCCV for patients who were on dabigatran was 51 days, while for warfarin, this was 82 $(P=0.001)$. The proportion of cancelation and rescheduling for warfarin patients was $21.4 \%$, while for dabigatran, this was $5.5 \%$. Patients were reviewed 6-20 weeks after DCCV; the success rate of DCCV for dabigatran patients was $61 \%$, whilst for warfarin patients, this was $52 \%$. The success rate went up to $69 \%$ for patients who received DCCV within 45 days of referral $(P=0.165)$.

Conclusion: This retrospective study supports clinical experience that DCCV is more likely to be successful when there is a shorter duration between the onset of AF and the date of DCCV, and shows that the use of dabigatran in comparison with warfarin facilitates earlier DCCV. 
Keywords: Atrial fibrillation; Cardioversion; Dabigatran; Direct current cardioversion; Warfarin

\section{INTRODUCTION}

Atrial fibrillation (AF) is a common arrhythmia affecting $1 \%$ of the general population increasing to $18 \%$ for those over 80 years old [1]. AF can cause turbulence in the blood flow within the heart resulting in clot formation. Clots can then migrate to the peripheral circulation resulting in stroke or limb thromboembolism [2-4]. This risk ranges from 5 to $7 \%$ in non-anticoagulated patients and is affected by other factors reflected in the $\mathrm{CHA}_{2} \mathrm{DS}_{2}$-VASc risk score: congestive heart failure, hypertension, age, diabetes mellitus, previous stroke, vascular disease history, and gender $[5,6,10]$.

Cardioversion with restoration of sinus rhythm can be achieved either pharmacologically or electrically. The most effective treatment for $\mathrm{AF}$ is direct current cardioversion (DCCV) [1]. However, this procedure can increase the risk of thromboembolism. The current recommendation is, therefore, to anticoagulate for at least 3 weeks before cardioversion and 4 weeks after the procedure to minimize the risk of embolization [7-11]. The risk of thromboembolism with adequate anticoagulation is as low as $0.7-0.8 \%$ [9]. Traditionally, the vitamin $\mathrm{K}$ antagonist, warfarin, has been used; however, this agent has considerable limitations as it can take time to get patients into target international randomized ratio (INR) range, and they run the risk of having DCCV canceled if their INR is out of range. The rate of success of DCCV in AF is largely affected by the duration of the AF; a shorter duration of $\mathrm{AF}$ is associated with a higher rate of success of DCCV and less relapse [15]. The use of DOACs in this setting to achieve rapid stable anticoagulation is, therefore, an attractive option.

The availability of the direct oral anticoagulants (DOACs) has dramatically changed the anticoagulation landscape. Dabigatran was the first DOAC approved for stroke prevention in AF. Dabigatran is a direct thrombin inhibitor (DTI) that has several advantages over warfarin. Dabigatran has rapid onset of action with peak plasma concentration within 60 min and a half-life between 12 and $17 \mathrm{~h}$ [12]. Dabigatran has a stable pharmacokinetic profile, and there is, therefore, no need to monitor use with blood tests in most patients [12]. This study aimed to compare the safety and efficacy of dabigatran and warfarin around DCCV in terms of stroke prevention, time taken to get to $\mathrm{DCCV}$, and the success of cardioversion in achieving sinus rhythm.

\section{METHODS}

A retrospective study of sequential patients referred for elective DCCV to Basingstoke and North Hampshire Hospital over 12 months running from September 2013 to September 2014. Patients were divided into two cohorts; Cohort A received dabigatran, while Cohort B was managed with warfarin. All patients with non-valvular AF planned for DCCV were included in the study. Patients managed with chemical cardioversion and those with mechanical valves and severe valvular heart disease were excluded from the study. Patients who started on anticoagulation with warfarin or dabigatran for DCCV were eligible for the study. The choice of agent determined following an informed discussion with the patient. Risks and 
benefits of oral anticoagulant have been discussed. Those already on warfarin or dabigatran for another indication (pulmonary embolism) were also included.

Patients who were on warfarin received variable dosing according to their INR. Their INR was checked weekly until the time of DCCV with target INR of 2-3. In line with normal practice, if the INR was not within the therapeutic range, the procedure was canceled pending adjustment of the dose of warfarin until the INR within the therapeutic range. Patients who were on dabigatran had baseline screening blood tests with coagulation profile, urea and electrolyte (U\&Es) and liver function tests (LFT) with no further blood tests if results were normal/stable. Only patients with stable renal function and creatinine clearance above $30 \mathrm{~mL} / \mathrm{min}$ commenced on dabigatran. Dabigatran was initiated at a dose of $110 \mathrm{mg}$ twice daily for people over 75 years old and $150 \mathrm{mg}$ twice daily for people less than 75 years old. On the date of the procedure, a written consent obtained from the patient after a discussion with risks and benefits of DCCV. In addition, the duration of dabigatran therapy was reviewed ensuring that a full course of 3 weeks had been taken, and if more than two doses had been missed, the procedure was canceled and rescheduled for another date.

The following data were collected: patient diagnosis, patient demographics, comorbidities, including cardiovascular risk factors $\left(\mathrm{CHA}_{2} \mathrm{DS}_{2}-\mathrm{VASc}\right)$, time between the referral for $\mathrm{AF}$ and the date of $\mathrm{DCCV}$, the rate of cancelation and rescheduling of DCCV, and the success rate of DCCV in restoring sinus rhythm. Complications of oral anticoagulant with DCCV were monitored for whole number of patients. Clinical outcomes, including cerebrovascular accident, transient ischemic attack, and peripheral arterial embolism, and bleeding events, were evaluated during 6-8 weeks of post-procedure follow-up.

Data were analyzed using the SPSS Statistics (SPSS Inc., Chicago, IL, USA) version 17.0. Differences between categorical values were analyzed using Pearson's Chi-square test and Fisher's exact test, while the Mann-Whitney $U$ test was used for continuous values. A $P$ value less than 0.050 was considered statistically significant.

This article is based on previously conducted procedures and does not involve any new studies of human or animal subjects performed by any of the authors.

\section{RESULTS AND DISCUSSION}

During the period of 12 months from September 2013 to September 2014, 129 patients were referred for elective DCCV for the treatment of AF with 107 patients actually receiving DCCV. The majority of referred patients 98.1\% (105 out of 107) was newly started on oral anticoagulants, and only two (1.9\%) patients were already receiving anticoagulants for the indication of pulmonary embolism. Fifty-four patients who received DCCV were on dabigatran (50.5\%; Cohort A), 42 patients were on warfarin (39.2\%; Cohort B), and 11 patients were on another DOAC (10.2\%).

Twenty-two patients were canceled for various reasons; 4 patients with low INR (18\%), 4 patients (18\%) returned spontaneously to sinus rhythm, while the remaining cancelations were either because the patient was too unwell to receive DCCV or because they had been referred for ablation.

The majority of the referred patients (96 patients; $89.7 \%$ ) had a low $\mathrm{CHA}_{2} \mathrm{DS}_{2}$-VASc score of between 0 and 3 , while only $10.3 \%$ (11 out of 107) had a $\mathrm{CHA}_{2} \mathrm{DS}_{2}$-VASc score of between 4 
and 9. For patients receiving dabigatran, the average $\mathrm{CHA}_{2} \mathrm{DS}_{2}$-VASc was $1.9 \pm 1.8$, while for warfarin, the average was $2.3 \pm 1.3$ with no statistical significance $(P=0.291)$.

The average age of included patients was 65.45 years, and there was no statistical significance in age between those on dabigatran and those on warfarin. The total number of male patients was 70 , and the total number of females was 26 , a ratio of $2.7: 1$. In terms of comorbidities in the total number of patients: 38 had congestive heart failure, 36 had hypertension, 11 had diabetes, 14 had a history of vascular disease, and 5 had previous cerebrovascular disease. There was no statistical difference in comorbidities with $\mathrm{CHA}_{2} \mathrm{DS}_{2}$-VASc between Cohort $\mathrm{A}$ and Cohort B (Table 1).
The average number of days between the date of referral for DCCV and the date of DCCV for patients who were on dabigatran was 51 days, while for patients on warfarin, this was 80 days $(P=0.001)$; for those who were on another DOAC, this was 50 days (Table 1 ).

The proportion of cancelation and rescheduling to a later date because of suboptimal INR for warfarin patients was $21.4 \%$ (9 out of 42 patients). In contrast, those who received dabigatran had a low rate of rescheduling with only three patients (5.5\%) having DCCV postponed due to missing doses (Table 1).

The percentage of immediate success of DCCV with achievement of sinus rhythm was $86 \%$. The majority of the patients (73\%) received one DCCV; $16 \%$ and $11 \%$ required 2

Table 1 Background data and outcome: Cohort A versus Cohort B

\begin{tabular}{llll}
\hline Category & Dabigatran (Cohort A) & Warfarin (Cohort B) & P value \\
\hline Number of patients, $n$ & 54 & 42 & - \\
Mean age \pm SD (range), years & $64.0 \pm 10.9(25-82)$ & $66.9 \pm 8.0(45-84)$ & $0.124^{\mathrm{a}}$ \\
Gender, $n$ & & & $0.772^{\mathrm{b}}$ \\
Male & 40 & 30 & \\
Female & 14 & 12 & \\
Heart failure, $n$ & 20 & 18 & $0.563^{\mathrm{b}}$ \\
Hypertension, $n$ & 23 & 13 & $0.795^{\mathrm{b}}$ \\
Diabetes mellitus, $n$ & 4 & 7 & $0.158^{\mathrm{c}}$ \\
Vascular disease, $n$ & 7 & 7 & $0.610^{\mathrm{c}}$ \\
Cerebrovascular accident, $n$ & 3 & 2 & $0.862^{\mathrm{c}}$ \\
Mean CHA ${ }_{2}$ DS ${ }_{2}$-VASc score \pm SD & $1.9 \pm 1.8$ & $2.3 \pm 1.3$ & $0.291^{\mathrm{a}}$ \\
Interval between referral and DCCV (days) & 51 & 80 & $0.001^{\mathrm{a}}$ \\
Cancelation and rescheduling of DCCV & 3 & 9 & $0.219^{\mathrm{c}}$ \\
DCCV with successful outcome & 33 & 22 & $0.391^{\mathrm{b}}$ \\
\hline
\end{tabular}

$D C C V$ direct current cardioversion, $S D$ standard deviation

a Mann-Whitney $U$ test

b Pearson's Chi-square test

c Fisher's exact test 
and 3 DCCV, respectively. At 6-20 week review following DCCV, the overall success rate was $57 \%$ (61 patients out of 107), and the proportion of patients who failed to maintain sinus rhythm was 46 out of 107 (43\%). For those patients on dabigatran, the success rate was $61 \%$ (33 out of 54), and the failure rate was 39\% (21 patients out of 54; Table 1). In comparison, the success rate for patients on warfarin was $52 \%$ (22 patients out of 42; Table 1), and the failure rate were $48 \%$ (20 out of 42 ). Six patients who received other DOACs had successful DCCV. There were no reported cases of cerebrovascular accident, transient ischemic attack, and peripheral arterial embolism or bleeding events in patients who received dabigatran, warfarin, or other DOACs. In addition, no discontinuation of any of the drugs was reported.

As previous studies have shown that shorter duration of AF associated with higher success rate of DCCV and less relapse [15], analysis was made for those patients who had AF duration of $\leq 45$ days. Review of patients with time between referral and date of DCCV $\leq 45$ days included 32 patients out of 107 (30\%). Twenty-one patients were on dabigatran, 7 patients were on warfarin, and 4 patients were on another DOAC. At 6-20 week review post-DCCV, the overall success of DCCV in restoring sinus rhythm was 22 patients out of 32 (69\%; $P=0.165$; Table 2) reflecting a higher success rate in this cohort. This finding was not statistically significant due to the relatively small number of patients. There were a high number of dabigatran patients receiving DCCV within 45 days compared to warfarin, which indicates that dabigatran can be associated with more rapid DCCV and a shorter AF.

Patients with heart failure represented a large group of 38 (39.8\% of the total). Twenty of
Table 2 Analysis of patients who received direct current cardioversion within 45 days and outcome; patients with background of heart failure and outcome

\begin{tabular}{lccl}
\hline Category & $\begin{array}{l}\text { Number of } \\
\text { patients }\end{array}$ & $\begin{array}{l}\text { Success } \\
\text { rate }\end{array}$ & P value \\
\hline $\begin{array}{l}\text { Number of patients with } \leq 45 \text { days referral } \\
\text { Total }\end{array}$ & 32 & $22(69 \%)$ & 0.165 \\
$\begin{array}{l}\text { Cohort A } \\
\text { (dabigatran) }\end{array}$ & 21 & - & - \\
$\begin{array}{l}\text { Cohort B } \\
\text { (warfarin) }\end{array}$ & 7 & - & - \\
$\begin{array}{l}\text { Heart failure patients } \\
\text { Total }\end{array}$ & 38 & & \\
Cohort A & 20 & $28(73.7 \%)$ & 0.009 \\
(dabigatran) & & $17(85 \%)$ & 0.006 \\
Cohort B & 18 & & 0.327 \\
(warfarin) & & & \\
\hline
\end{tabular}

these patients received dabigatran, while 18 patients had warfarin. The total success rate was 73.7\% (28 patients; $P=0.009$ ). The percentage of the success of DCCV for heart failure who received dabigatran was $85 \%$ (17 patients; $P=0.006)$, while for warfarin patients, this was $61 \%$ (11 patients; $P=0.327$; Table 2 ).

One of the limitations of this study is the relatively small number of patients in this single-center study; however, the data are comparable with other published studies [1]. The relatively higher cost of dabigatran ( $£ 75.60$ per month) may limit its use in comparison with warfarin $(£ 0.86-1.67$ per month but with additional monitoring costs) [13]. In the UK, it is estimated that the overall cost for outpatient DCCV is approximately $£ 722$ [14], and this cost is predicted to be higher with cancelation and rescheduling. Dabigatran may, therefore, be a more cost-effective approach for DCCV. 


\section{CONCLUSIONS}

Shorter duration between the onset of AF and the date of DCCV is associated with a higher probability of successful DCCV. The use of dabigatran in comparison with warfarin facilitated earlier DCCV with a lower probability of rescheduling due to inadequate anticoagulation. Dabigatran was, therefore, associated with greater success from DCCV in our study. This is more convenient for patients and staff.

\section{ACKNOWLEDGMENTS}

No funding or sponsorship was received for this study or publication of this article. The article processing charges were funded by the authors. All named authors meet the International Committee of Medical Journal Editors (ICMJE) criteria for authorship for this manuscript, take responsibility for the integrity of the work as a whole, and have given final approval for the version to be published.

Disclosures. Sufyan Benamer, Debbie Lusty, and Tamara Everington declare that they have no conflicts of interest.

Compliance with Ethics Guidelines. This article is based on previously conducted procedures and does not involve any new studies of human or animal subjects performed by any of the authors.

Open Access. This article is distributed under the terms of the Creative Commons Attribution-NonCommercial 4.0 International License (http://creativecommons.org/licenses/ by-nc/4.0/), which permits any noncommercial use, distribution, and reproduction in any medium, provided you give appropriate credit to the original author(s) and the source, provide a link to the Creative Commons license, and indicate if changes were made.

\section{REFERENCES}

1. Choo WK, Fraser S, Padfield G, Rushworth GF, Bloe C, Forsyth P, Cross SJ, Leslie SJ. Dabigatran improves the efficiency of an elective direct current cardioversion service. $\mathrm{Br} \mathrm{J}$ Cardiol. 2014;21:29-32. doi:10.5837/bjc.2014.002.

2. Resnekov L, McDonald L. Complications in 220 patients with cardiac dysrhythmias treated by phased direct current shock, and indications for electroconversion. Br Heart J. 1967;29:926-36.

3. Lown B, Perlroth MG, Kaidbey S, Abe T, Harken DE. "Cardioversion" of atrial fibrillation: a report on the treatment of 65 episodes in 50 patients. N Engl J Med. 1963;269:325-31.

4. Jensen JB, Humphries JO, Kouwenhoven WB, Jude JR. Electroshock for atrial flutter and atrial fibrillation: follow-up studies on 50 patients. JAMA. 1965;194:1181-4.

5. Arnold AZ, Mick MJ, Mazurek RP, Loop FD, Trohman RG. Role of prophylactic anticoagulation for direct current cardioversion in patients with atrial fibrillation or atrial flutter. J Am Coll Cardiol. 1992;19:851-5. doi:10.1016/0735-1097(92)90530-Z.

6. Weinberg DM, Mancini GBJ. Anticoagulation for cardioversion of atrial fibrillation. Am J Cardiol. 1989;63:745-6.

7. Camm AJ, Lip GYH, De Caterina R, et al. 2012 focused update of the ESC guidelines for the management of atrial fibrillation. An update of the 2010 ESC guidelines for the management of atrial fibrillation. Developed with the special contribution of the European Heart Rhythm Association. Eur Heart J. 2012;33:2719-47.

8. Christopher G, Ajay Y, Rod PV. Safety of novel oral anticoagulant for direct current cardioversion in patients with atrial fibrillation and flutter. J Am Coll Cardiol. 2014; doi:10.1016/SO7351097(14)60443-5.

9. Fuster V, Rydén LE, Cannom DS, et al. ACC/AHA/ ESC 2006 guidelines for the management of patients with atrial fibrillation. Circulation. 2006;114:e257-3354. 
10. Singer DE, Albers GW, Dalen JE, Fang MC, Go AS, Halperin JS, Lip GY, Manning WJ, American College of Chest Physicians. Antithrombotic therapy in atrial fibrillation: American College of Chest Physicians evidence-based clinical practice guidelines (8th edition). Chest. 2008;133:546S-92S.

11. Steering and Publications committees of the ACUTE Study. Design of a clinical trial for the Assessment of Cardioversion Using Transesophageal Echocardiography (ACUTE multicenterstudy). Am J Cardiol. 1998;81:877-83.

12. Hankey GJ., Eikelboom JW. 2011. American Heart Association, Inc. Print ISSN: 0009-7322. Online ISSN:1524-4539.
13. British Medical Association and the Royal Pharmaceutical Society of Great Britain. British National Formulary. 65th ed. London: BMJ Publishing Group; 2013.

14. Department of Health. Payment by results in the NHS: tariff for 2013-2014. London: DoH; 2013.

15. Frick M, Frykman V, Jensen-Urstad M, Ostergren J, Rosengvist M. Factors predicting success rate and recurrence of atrial fibrillation after first electrical cardioversion in patients with persistent atrial fibrillation. Clin Cardiol. 2001;24(3):238-44. 